\title{
Letter to the Editor regarding the article "Relation of ADRB3, GEF, ROCK2 gene polymorphisms to clinical findings in overactive bladder"
}

\author{
Li Gao $^{1} \cdot$ Changkai Deng ${ }^{1}$ (i)
}

Received: 21 December 2020 / Accepted: 25 December 2020 / Published online: 13 January 2021

(C) The Author(s), under exclusive licence to Springer-Verlag GmbH, DE part of Springer Nature 2021

\section{Dear Editor}

We were pleased to read an original article entitled "Relation of ADRB3, GEF, ROCK2 gene polymorphisms to clinical findings in overactive bladder" published in World Journal of Urology in 2020 [1].

The authors investigated whether single-gene polymorphisms affecting adrenergic and cholinergic pathways are associated with $\mathrm{OAB}$ syndrome by a case-control study. Although the results in the study might be of interest, it appears to us that the data were not potent, because there is a serious concern. To fully assess the impact of the findings in this study, it is needed to settle the following question.

It was noted in the Results that "All three SNP genotype data were in agreement with Hardy-Weinberg equilibrium $(p>0.05)$ ". The authors stated in the Materials and methods of Statistical analysis that " $p<0.05$ was considered statistically significant". However, the genotype distribution for ADRB3 gene T > C polymorphism (ID: rs4994) was in fact departed from the Hardy-Weinberg equilibrium (HWE) with statistical significance in 60 healthy controls $(p=0.0003)$ (calculated from data in Table 1) [1].

To investigate the association between specific genotype and phenotype by the case-control study design, it is essential that the genotype distribution should conform to HWE $[2,3]$. Deviations from HWE in control subjects can indicate inbreeding, population stratification, and even problems in genotyping, and may bias the estimates of genetic effects in genetic association studies [2,3]. At last, these could result in false-positive findings or trustless conclusions. Therefore the findings in this study remain to be doubtful until they would be replicated by investigation of other cohorts in accordance with HWE.

Author contributions LG Data collection, data analysis, manuscript writing. CD Project development, management, manuscript writing.

\section{Compliance with ethical standards}

Conflict of interest Author Li Gao declares that she has no conflict of interest. Author Changkai Deng declares that he has no conflict of interest.

Ethical approval This article does not contain any studies with human participants or animals performed by any of the authors.

\section{References}

1. Firat E, Aybek Z, Akgün Ş et al (2020) Relation of ADRB3, GEF, ROCK2 gene polymorphisms to clinical findings in overactive bladder. World J Urol 38:2571-2575

2. Wigginton JE, Cutler DJ, Abecasis GR (2005) A note on exact tests of Hardy-Weinberg equilibrium. Am J Hum Genet $76: 887-893$

3. Zintzaras E (2010) Impact of Hardy-Weinberg equilibrium deviation on allele-based risk effect of genetic association studies and meta-analysis. Eur J Epidemiol 25:553-560

Publisher's Note Springer Nature remains neutral with regard to jurisdictional claims in published maps and institutional affiliations.

This comment refers to the article available online at https://doi. org/10.1007/s00345-019-03046-5.

Changkai Deng

15882420198@163.com

1 Department of Pediatric Surgery, School of Medicine, Chengdu Women's and Children's Central Hospital, University of Electronic Science and Technology of China, Chengdu 611731, China 